\title{
PREVISIBILIDADE NA INSTALAÇÃO IMEDIATA DE IMPLANTE CONE MORSE PELO PLANEJAMENTO DIGITAL E PROVISIONALIZAÇÃO IMEDIATA: RELATO DE CASO
}

\author{
PREDICTABILITY IN IMMEDIATE IMPLANT PLACEMENT OF MORSE TAPER BY \\ DIGITAL PLANNING AND IMMEDIATE PROVISIONALIZATION: CASE REPORT
}

\author{
Ángel José Sánchez REYES'; Geninho THOMÉ2; Carolina Accorsi CARTELLI³; Sérgio Rocha BERNARDES"; Marcos Boaventura de \\ MOURA $^{5}$; Larissa Carvalho TROJAN ${ }^{6}$ \\ 1 - Especialista em Dentística Restauradora pelo Instituto Latino Americano de Pesquisa e Ensino Odontológico (ILAPEO). Mestrando em \\ Implantodontia do Instituto Latino Americano de Pesquisa e Ensino Odontológico (ILAPEO). \\ 2 - Doutor em Implantodontia - São Leopoldo Mandic, Campinas. \\ 3 - Mestre e Especialista em Implantodontia pelo Instituto Latino Americano de Pesquisa e Ensino Odontológico (ILAPEO). \\ 4 - Doutor em Reabilitação Oral - Universidade de São Paulo (USP). Especialista em Prótese Dentária (APCD Bauru). \\ 5 - Doutorando em Clínica Odontológica área de Implantodontia e Prótese sobre implante - Universidade Federal de Uberlândia (UFU). Especialista \\ em Implantodontia - São Leopoldo Mandic, Brasília. \\ 6 - Doutora em Engenharia de Estruturas pela Universidade Federal de Minas Gerais (UFMG). Especialista em Ortodontia pelo Instituto Latino \\ Americano de Pesquisa e Ensino Odontológico (ILAPEO).
}

\section{RESUMO}

A instalação imediata de implantes em região estética é uma prática frequente, pois reduzir a remodelação óssea e tecidual. Os implantes com interface cone Morse apresentam resultados biológicos e estéticos satisfatórios a longo prazo, pois apresentam gap reduzido entre implante e componente protético e a interface fica distante do tecido ósseo. Este artigo tem como objetivo relatar a reabilitação estética de um incisivo central superior comprometido através da instalação de um implante cone Morse utilizando a técnica da cirurgia guiada com provisionalização imediata. Paciente com 40 anos de idade, do sexo masculino, apresentava incisivo central superior (\#21) com tratamento endodôntico prévio, recessão gengival vestibular, escurecimento coronário e mobilidade. O caso clínico apresentado mostrou que, após 12 meses, resultados precisos e estéticos são possíveis de alcançar com a instalação de implantes em alvéolos pós-extração e instalação de um dente provisório imediato em regiões estéticas.

Palavras-chave: Implantes dentários; Materiais dentários; Prótese dentária.

\section{INTRODUÇÃO}

O tratamento com implantes osseointegrados é considerado um tratamento viável, capaz de tratar o edentulismo ${ }^{1}$. Regiões de alta exigência estética e condições biológicas limitantes podem ser desafiantes na hora de instalar um implante na posição ideal, mantendo os tecidos circundantes saudáveis ao longo do tempo². Na região anterior da maxila, em áreas pós-extração conseguir um posicionamento ideal do implante pode ser desafiador até para cirurgiões-dentistas experientes ${ }^{3}$. A espessura reduzida da parede óssea vestibular é um fator limitante na busca por um resultado estético adequado, o que tem levado cirurgiões-dentistas e pesquisadores a buscarem protocolos cirúrgicos mais conservadores e ao mesmo tempo mais previsíveis ${ }^{3}$.

A remoção de uma raiz dentária leva sempre a uma remodelação do osso remanescente. A instalação de implantes imediatos pós-extração dentária quando bem executada pode ser considerada uma alternativa ao protocolo cirúrgico original, com resultados clínicos similares ${ }^{2,3}$. Existe uma melhor preservação dos tecidos adjacentes após instalação de implantes imediatos em alvéolos pós-extração quando colocados em carga imedia$\mathrm{ta}^{2,4}$. Um dos principais requisitos da técnica é a obtenção de uma estabilidade primária do implante, motivo pelo qual a engenharia dos implantes tem evoluído, tentando desenvolver implantes com macroestruturas que consigam atingir a estabilidade nos diferentes cenários cirúrgicos ${ }^{5}$.

A provisionalização imediata após instalação do implante apresenta a vantagem de guiar o reparo do tecido mole, proporcionando um perfil de emergência mais harmônico. Uma restauração natural e simétrica com o dente contralateral em região anterior de maxila se tornou o objetivo principal das reabilitações realizadas pelos cirurgiões-dentistas, não somente pela função, mas pela estética e satisfação dos pacientes ${ }^{6,7}$.

A plataforma (switching) do tipo cone Morse tem sido amplamente indicada por apresentar características que favorecem a resposta biológica do tecido peri-implantar, como o afastamento do gap existente na interface abutment/implante do osso e a 
redução do componente, além da diminuição do desaperto de parafusos $^{8}$, problema recorrente nos implantes do tipo hexágono externo9.

O conceito do planejamento por software e cirurgias guiadas combinadas com carga imediata foi clinicamente introduzido em quase duas décadas ${ }^{10}$. Os tratamentos iniciais evoluíram para a cirurgia guiada de implante assistida por computador. O uso de software de planejamento cirúrgico com arquivos DICOM da tomografia computadorizada de feixe cônico (TCFC) pode ser convertido em imagens tridimensionais (3D), o que permitirá um planejamento virtual preciso da posição ideal dos implantes ${ }^{10-12}$.

O presente artigo teve como objetivo relatar um caso clínico de reabilitação de um incisivo central superior esquerdo comprometido, através da instalação de um implante cone Morse e provisionalização imediata cimentada.

\section{RELATO DE CASO CLÍNICO}

Paciente M.A., gênero masculino, 40 anos de idade, compareceu ao Instituto Latino Americano de Pesquisa e Ensino Odontológico (ILAPEO) para tratamento do dente 21. No atendimento inicial foi realizada avaliação do paciente, onde foram coletadas as informações de saúde geral, avaliada a oclusão, e feita uma radiografia periapical do dente 21 . Clinicamente o paciente apresentava mordida cruzada, o dente apresentava mobilidade e escurecimento da coroa clínica comprometendo a estética do sorriso (Figura 1A). Radiograficamente o dente apresentava tratamento endodôntico com selamento apical deficiente e aspecto radiolúcido no ápice radicular (Figura 1B). O tratamento proposto pela equipe de profissionais foi a extração do elemento 21, instalação imediata de um implante através da cirurgia guiada e provisionalização imediata.

\section{Confecção do guia cirúrgico}

foram realizadas moldagens superior e inferior do paciente para confecção de modelos em gesso. Uma TCFC para a avaliação da espessura óssea (Figura 1C) e planejamento virtual da posição ideal do implante foi realizada. Os modelos de gesso foram escaneados para auxiliar no planejamento virtual cirúrgico-protético. No planejamento digital foi observada disponibilidade óssea para a instalação de um implante de 3,75 x 16 mm.
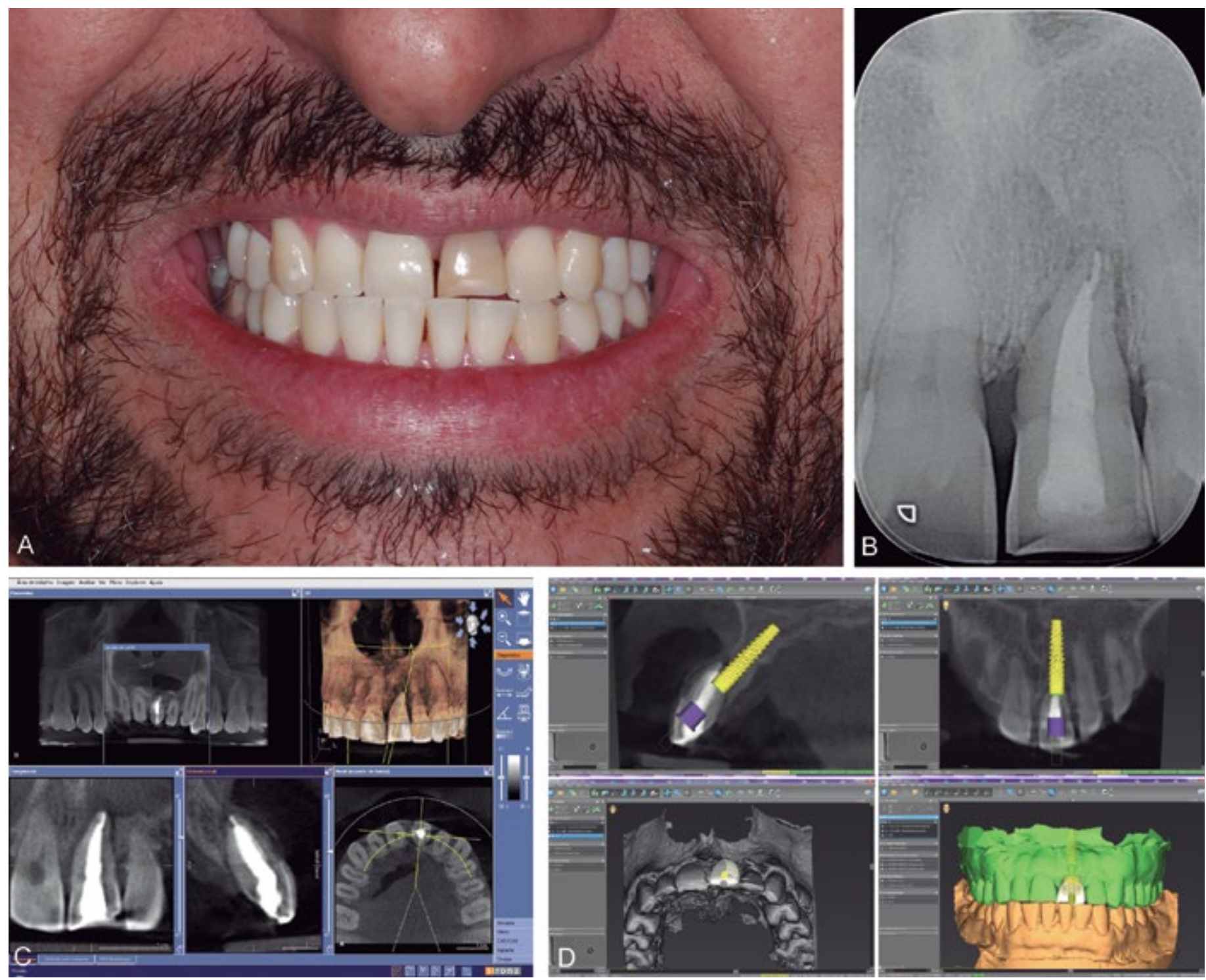

Figura 1 - Aspecto Inicial. A: Foto inicial do caso clínico; B: Radiografia periapical inicial; C: Cortes tomográficos iniciais; D: Planejamento tomográfico/digital do caso. 
O planejamento protético foi realizado para personalização de um munhão de zircônia e coroa provisória, sobre uma base de titânio compatível com a interface do implante (Figura 1D). Após a aprovação do planejamento, o guia cirúrgico foi impresso, e sua adaptação testada no modelo (Figura 2A) e em boca.

\section{Fase cirúrgica}

Após anestesia infiltrativa, foi realizada extração dentária minimamente traumática sem retalho, com utilização de um fórceps $\mathrm{n}^{\circ} 150$. O alvéolo foi curetado e irrigado com soro fisiológico e iniciou-se o preparo do leito ósseo com auxílio do guia cirúrgico.

Foi realizada uma radiografia periapical transoperatória com fresa 2.0 para conferir a precisão do posicionamento do guia e direção da fresagem (Figura 2B). A perfuração foi iniciada pela fresa-lança na parede palatina, para guiar a perfuração preservando a parede vestibular. Em seguida, foram utilizadas as outras fresas em sequência, sendo $2.0 \mathrm{~mm}, 3.5 \mathrm{~mm}, 2.8 / 3.5 \mathrm{~mm}$ e $3.75 \mathrm{~mm}$ com subfresagem, em uma profundidade de $18 \mathrm{~mm}$ da crista óssea e $20 \mathrm{~mm}$ do contorno gengival. Esta conduta permitiu a instalação do implante Helix GM Acqua de 3,75 x 16 mm (Neodent - Curitiba, Brasil) (Figura 2C) 2 mm infra-ósseo, promovendo um adequado perfil de emergência da futura prótese. O implante foi instalado com um torque de $60 \mathrm{Ncm}$, permitindo a realização da provisionalização imediata. $\mathrm{O}$ alvéolo foi preenchido com biomaterial (Cerabone - Straumann, Basel, Suíça).

\section{Provisionalização imediata}

Com o travamento obtido na instalação do implante foi possível confeccionar uma coroa provisória sobre o componente protético selecionado pelo planejamento virtual. Foi escolhida a prótese cimentada para assegurar um perfil de emergência estético, com uso de uma base de titânio GM de 3.5 x 4.0 x $3.5 \mathrm{~mm}$ (Neodent), instalada sobre o implante com um torque de $20 \mathrm{Ncm}$. Um coping personalizado de zircônia foi cimentado sobre essa base de titânio (Figura 3A) e em seguida, cimentada a coroa provisória imediata (Figuras 3B e 3C). Os ajustes oclusais foram realizados no provisório, aliviando os contatos excessivos nos movimentos excursivos no período de osseointegração, porém mantendo a protése em oclusão. O paciente retornou com 1 mês para avaliação da condição clínica e radiográfica da reabilitação (Figura 4).

\section{Fase protética definitiva}

Para reabilitação definitiva, optou-se pela confecção de uma coroa de dissilicato de lítio cimentada sobre o munhão personalizado em zircônia, que apresenta estética superior ao metal e opacidade suficiente para mascarar o componente metálico. $\mathrm{O}$ provisório instalado no dia da cirurgia condicionou o perfil de emergência até o momento da moldagem definitiva, que acorreu 8 meses após a cirurgia.

Para garantir uma reprodução fiel do perfil de emergência para a prótese definitiva, foi realizado um refinamento do preparo do componente personalizado em zircônia e, então, realizada a moldagem de transferência e registros oclusais (Figura 5A). A moldagem para coroa definitiva foi realizada utilizando um casquete de moldagem feito em resina acrílica (Pattern resin LS, GC, Alsip, Japão) adaptado ao preparo (Figura 5B). O material selecionado para moldagem com casquete foi o silicone de condensação (Speedex, Coltene, Altstätten, Suíça).
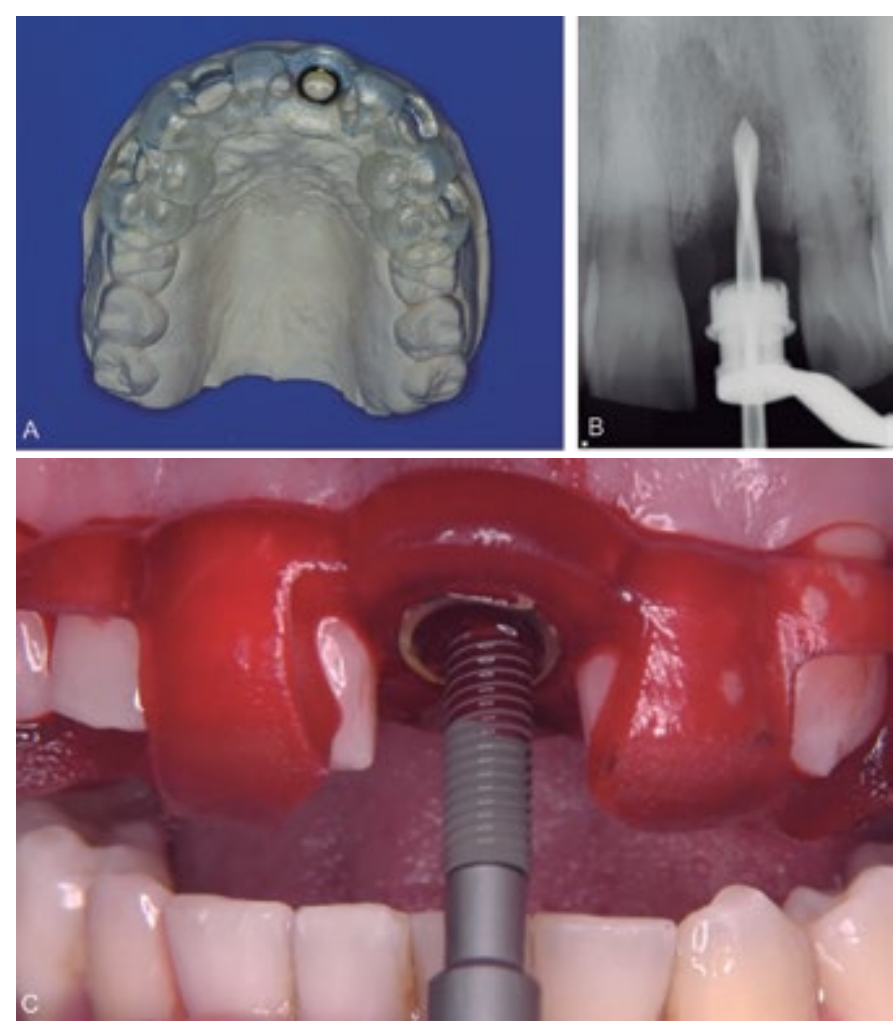

Figura 2 - Parte cirúrgica. A: Guia cirúrgico em posição no modelo de gesso; B: Radiografia periapical transoperatória com utilização da broca $2.0 \mathrm{~mm}$ mostrando o direcionamento correto da fresagem; C: Instalação do implante com auxílio do guia cirúrgico Brånemark PI.
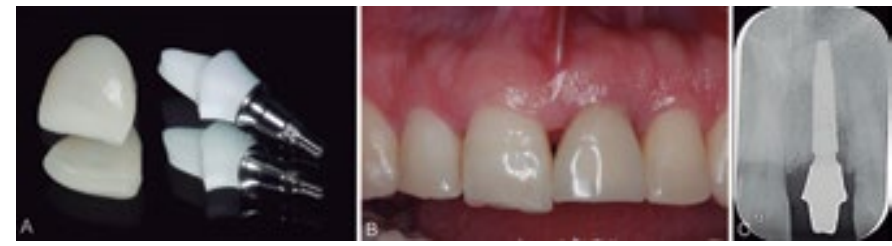

Figura 3 - Provisório imediato. A: Base de titânio com coping de zircônia cimentado e coroa provisória em resina acrílica; B: Aspecto clínico imediato da coroa provisória; C: Radiografia periapical da instalação imediata do implante e provisório.

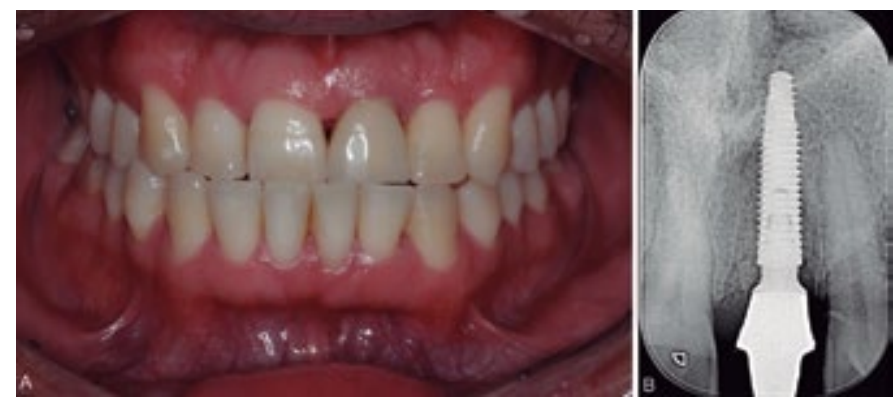

Figura 4 - Acompanhamento de 1 mês. A: Aspecto clínico; B: Radiografia periapical.
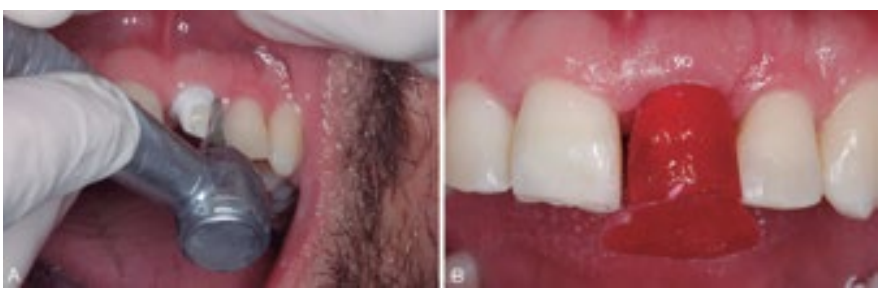

Figura 5 - Moldagem definitiva. A: Refinamento do preparo para moldagem; B: Casquete de moldagem para realização da moldagem definitiva. 
O paciente foi acompanhado clinicamente e radiograficamente por um período de 12 meses. Os tecidos duros e moles se mantiveram com boa estabilidade. Clinicamente, foi possível observar uma remodelação mínima dos tecidos moles peri-implantares (Figura 6A). Radiograficamente foi observado que o implante estava infra-ósseo, a distância da plataforma do implante até a crista óssea mesial era de 1,88 $\mathrm{mm}$ de altura e da plataforma do implante até a crista distal 1,93 $\mathrm{mm}$ de altura, os componentes estavam bem adaptados (Figura 6B).

\section{DISCUSSÃO}

A manutenção da estabilidade tecidual ao redor dos tecidos peri-implantares é um desafio para os cirurgiões-dentistas e pesquisadores ${ }^{2}$, principalmente na região anterior da maxila, devido sua alta demanda estética. Diversos protocolos têm sido desenvolvidos para solucionar essa problemática. Desde cirurgias em diferentes tempos até a utilização de diferentes materiais para regeneração óssea. A cirurgia em dois tempos cirúrgicos gera um maior estresse para o paciente devido o número de procedimentos realizados, além de que a técnica não impede o colapso dos tecidos após a extração do dente. Nesses casos podem ser necessários procedimentos de enxertia para conseguir recuperar o volume tecidual perdido na remodelação que acontece pós-extração ${ }^{13}$. Existem evidências científicas afirmando que a instalação do implante imediato pós-extração e provisionalização imediata favorecem a manutenção do volume tecidual pelo micro estímulo gerado no osso ${ }^{2,4,13}$.

Sugere-se que o preenchimento do alvéolo deve ser realizado sempre que um dente for extraído e apresentar gaps maiores que $2 \mathrm{~mm}^{14,15}$. O padrão ouro para enxertos ósseos até os dias de hoje continua sendo o osso autógeno, mas a sua utilização nas técnicas de enxertia requer um segundo leito cirúrgico ${ }^{14-16}$. Mesmo que o osso autógeno continue sendo o padrão ouro, é possível a obtenção de resultados altamente favoráveis com o uso dos biomateriais, sem precisar de mais um leito cirúrgico ${ }^{13}$. O biomaterial usado para o preenchimento do alvéolo foi um substituto ósseo do tipo xenógeno indicado para manter o volume do osso alveolar em casos de instalação de implantes imediatos ${ }^{17,18}$.

A instalação de implantes em alvéolos frescos pode ser desafiadora até para cirurgiões mais experientes ${ }^{15}$. A precisão da fresagem é uma fase de suma importância para obter uma estabilidade primária. A utilização de guias prototipados inclusive em área de pós-extração dentária aumenta a precisão do procedimento, simplificando a técnica para o cirurgião, aumentando a probabilidade de obter uma estabilidade primária e prevendo a instalação do implante na posição ideal ${ }^{19}$. Outro fator que influencia na obtenção da estabilidade primária é a qualidade do osso. Por isso existem vários desenhos de implantes com o objetivo de se conseguir estabilidade primária em ossos de qualidade baixa. O implante utilizado neste caso é um implante cônico que na sua porção cervical tem roscas compactantes e, na porção apical, roscas cortantes, com isso é considerado um implante mais versátil, podendo ser indicado para todos os tipos de ossos (tipo I, II ,III, IV). A instalação dos implantes $2 \mathrm{~mm}$ abaixo da a crista óssea, também é um fator que influencia positivamente na manutenção dos tecidos peri-implantares, principalmente nos casos de alta demanda estética ${ }^{5,20,21}$.

Na literatura têm sido reportadas falhas mecânicas nos componentes de zircônia para confecção de próteses sobre implantes.

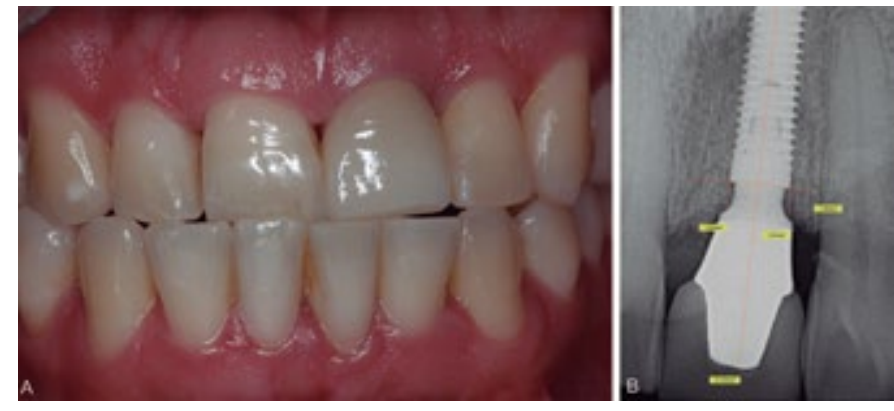

Figura 6 - Acompanhamento de 12 meses. A: Aspecto clínico do caso; B: Radiografia periapical.

Como uma alternativa de promover tanto vantagens estéticas quanto mecânicas, têm sido utilizados componentes híbridos de zircônia com base em titânio ${ }^{22}$. Além de ter uma coloração favorável que potencializa a obtenção de um resultado estético, foi observada uma superioridade no comportamento biológico da zircônia quando em contato com os tecidos moles em relação aos componentes de titânio. $\mathrm{O}$ uso de um componente personalizado em zircônia permite fazer ajustes sem a necessidade de trocar ou remover o componente, podendo assim adaptar o componente as remodelações do tecido mole que acontecem durante período de cicatrização ${ }^{22}$.

Com o auxilio de um planejamento digital e a confecção de um guia prototipado para a instalação do implante na posição ideal em relação ao planejamento protético, junto com utilização de um componente personalizado de zircônia com base de titânio e preenchimento do alvéolo com biomaterial; mostrou-se possível a obtenção de um resultado altamente previsível, reduzindo a morbidade, otimizando o tempo clínico do procedimento, devolvendo estética, função, e mantendo uma estabilidade tecidual nos tecidos ao redor do implante em casos de implante imediato em área estética. A mordida cruzada interferiu na estética final do caso, mas o paciente não aceitou passar por um período de tratamento ortodôntico para melhoria da oclusão.

\section{CONCLUSÃO}

A instalação imediata de implantes com interface cônica tipo cone Morse, com auxílio do planejamento digital e provisionalização imediata mostrou ser um protocolo exitoso para o tratamento de dentes com indicação de extração em área estética, sendo capaz de minimizar a remodelação óssea e tecidual. Além da escolha de cerâmicas odontológicas com propriedades óticas elevadas, como opalescência, fluorescência e translucidez.

\section{REFERÊNCIAS}

01. Adell R, Lekholm U, Rockler B, Brånemark PI. A 15-year study of osseointegrated implants in the treatment of the edentulous jaw. International Journal of Oral Surgery. 1981; 10(6): 387-416.

02. Kan JY, Rungcharassaeng K, Lozada JL, Zimmerman G. Facial gingival tissue stability following immediate placement and provisionalization of maxillary anterior single implants: a 2- to 8-year follow-up. The International Journal of Oral \& Maxillofacial Implants. 2011; 26(1): 179-87.

03. Buser D, Chappuis V, Belser UC, Chen S. Implant placement post extraction in esthetic single tooth sites: when immediate, when early, when late? Periodontology 2000. 2017; 73(1): 84-102. 
04. Roe P, Kan JY, Rungcharassaeng K, Caruso JM, Zimmerman G, Mesquida J. Horizontal and vertical dimensional changes of peri-implant facial bone following immediate placement and provisionalization of maxillary anterior single implants: a 1-year cone beam computed tomography study. The International Journal of Oral \& Maxillofacial Implants. 2012; 27(2): 393-400.

05. Martin C, Thomé G, Melo AC, Fontão FN. Peri-implant bone response following immediate implants placed in the esthetic zone and with immediate provisionalization--a case series study. Oral and Maxillofacial Surgery. 2015; 19(2): 157-63.

06 . Grunder U. Crestal ridge width changes when placing implants at the time of tooth extraction with and without soft tissue augmentation after a healing period of 6 months: report of 24 consecutive cases. The International Journal of Periodontics and Restorative Dentistry. 2011; 31(1): 9-17.

07.Zucchelli G, Sharma P, Mounssif I. Esthetics in periodontics and implantology. Periodontology 2000. 2018; 77(1): 7-18.

08. Castro DS, Araujo MA, Benfatti CA, Araujo Cdos R, Piatelli A, Perrotti $\mathrm{V}$, et al. Comparative histological and histomorphometrical evaluation of marginal bone resorption around external hexagon and Morse cone implants: an experimental study in dogs. Implant Dentistry. 2014; 23(3): 270-6.

09. Moura MB, Rodrigues RB, Pinto LM, de Araújo CA, Novais VR, Júnior PCS. Influence of Screw Surface Treatment on Retention of Implant-Supported Fixed Partial Dentures. Journal of Oral Implantology. 2017; 43(4): 254-60.

10. Lopes A, Maló P, Araújo NM, Sánchez-Fernández E, Gravito I. The NobelGuide ${ }^{\circledast}$ All-on- $4^{\circledR}$ Treatment Concept for Rehabilitation of Edentulous Jaws: A Retrospective Report on the 7-Years Clinical and 5-Years Radiographic Outcomes. Clinical Implant Dentistry and Related Research. 2017; 19(2): 233-44.

11. Colombo M, Mangano C, Mijiritsky E, Krebs M, Hauschild U, Fortin T. Clinical applications and effectiveness of guided implant surgery: a critical review based on randomized controlled trials. BMC Oral Health. 2017; 17(1): 150.

12. Vercruyssen M, Hultin M, Van Assche N, Svensson K, Naert I, Quirynen M. Guided surgery: accuracy and efficacy. Periodontology 2000. 2014; 66(1): 228-46.
13. Benic GI, Mir-Mari J, Hämmerle CH. Loading protocols for single-implant crowns: a systematic review and meta-analysis. The International Journal of Oral \& Maxillofacial Implants. 2014; 29(suppl.): 222-38

14. Rosa JC, Rosa AC, Rosa DM, Zardo CM. Immediate Dentoalveolar Restoration of compromised sockets: a novel technique. European Journal of Esthetic Dentistry. 2013; 8(3): 432-43.

15. Rosa JC, Rosa AC, Fadanelli MA, Sotto-Maior BS. Immediate implant placement, reconstruction of compromised sockets, and repair of gingival recession with a triple graft from the maxillary tuberosity: a variation of the immediate dentoalveolar restoration technique. The Journal of Prosthetic Dentistry. 2014; 112(4): 717-22.

16. Burchardt $\mathrm{H}$. The biology of bone graft repair. Clinical Orthopaedics and Related Research. 1983; (174): 28-42.

17. Jensen SS, Bornstein MM, Dard M, Bosshardt DD, Buser D. Comparative study of biphasic calcium phosphates with different HA/TCP ratios in mandibular bone defects. A longterm histomorphometric study in minipigs. Journal of Biomedical Materials Research Part B: Applied Biomaterials. 2009: 90(1): 171-81.

18. Sanz M, Vignoletti F. Key aspects on the use of bone substitutes for bone regeneration of edentulous ridges. Dental Materials. 2015; 31(6): 640-47.

19. Motta M, Monsano R, Velloso GR, Silva JCO, Luvizuto ER, Margonar $R$, et al. Guided surgery in esthetic region. Journal of Craniofacial Surgery. 2016; 27(3): 262-5.

20. Passoni BB, Castro DSM, Araújo MA, Araújo CD, Piatelli A, Benfatti CA. Influence of immediate/delayed implant placement and implant platform on the peri-implant bone formation. Clinical Oral Implants Research. 2016; 27(11): 1376-83.

21. Degidi M, Daprile G, Piattelli A. Implants inserted with low insertion torque values for intraoral welded full-arch prosthesis: 1-year followup. Clinical Implant Dental and Related Research. 2012; 14(suppl.): e39-e45.

22. Harlos MM, Silva TB, Peruzzo DC, Napimoga MH, Joly JC, Martinez EF. In vitro microbiological analysis of bacterial seal in hybrid zirconia abutment tapered connection. Implant Dentistry. 2017; 26(2): 245-9.

\section{ABSTRACT}

The immediate placement of implant in fresh sockets in the aesthetic area is a frequent practice as it reduces bone and tissue remodeling. Morse taper implants present satisfactory biological and aesthetic results in the long term, since they present a reduced gap between implant and prosthetic component and this interface is distant from bone. This article aims to report the aesthetic restoration of a compromised central upper incisor with the placement of a Morse taper implant using guided surgery with immediate provision. A 40-year-old male patient had a central upper incisor (\#21) with previous endodontic treatment, vestibular gingival recession, coronary browning, and mobility. The clinical case presented showed that, after 12 months, precise and aesthetic results are possible to achieve with the placement of implants in post-extracting alveolus and installation of an immediate provisional tooth in esthetic regions.

Keywords: Dental implants; Dental materials; Dental prothesis.

\section{AUTOR PARA CORRESPONDÊNCIA}

Marcos Boaventura de Moura

Departamento de Oclusão, Prótese Fixa e Materiais

Dentários, Faculdade de Odontologia - Universidade

Federal de Uberlândia
Av. Pará, 1720, Bloco 4LA, $3^{\circ}$ Piso, Sala 42, Campus Umuarama CEP: 38405320, Uberlândia-MG, Brasil

Telefone/Fax: (34) 32258105

E-mail: boaventura.mm@hotmail.com 